\title{
La inscripción árabe de la Alhambra de origen desconocido. El poeta oriental del monumento*
}

\author{
An Arabic Inscription of the Alhambra. The Oriental \\ Poet of the Monument
}

\author{
José Ramírez del Río \\ Universidad de Córdoba \\ https://orcid.org/0000-0002-9329-5658
}

Las inscripciones de la Alhambra y del Generalife han sido estudiadas desde hace más de cuatrocientos años y se ha determinado tanto la autoría de los poemas presentes en los muros como su sentido. En este artículo documentamos uno de los dos poemas cuya autoría no había sido determinada hasta la fecha y mostramos el sentido de la misma en el reino nazarí de Granada y en el norte de África.

Palabras clave: Alhambra; Generalife; Epigrafía árabe; Poemas; Ibn al-Ŷawzī; Al-Ḥasan al-Bașrī.
The epigraphic poems written in Arabic in the Alhambra and Generalife have been studied for more than four hundred years. Therefore, their authorship and meaning have been determined. In the present paper, I will analyze one of the two poems that had not received any critical attention so far and, at the same time, I will try to explain the meaning of this poem within the Nașrid and North African context.

Key words: Alhambra; Generalife; Epigraphic Arabic Poems; Poetry; Ibn al-Jawzī; Al-Hasan al-Bașrī.

\section{Introducción}

La Alhambra de Granada es uno de los monumentos más destacados de España y ha recibido atención muy detallada de estudiosos de todo tipo de disciplinas, desde la Historia del Arte hasta la Arquitectura o el Arabismo. La simple enumeración de la bibliografía generada superaría con creces las posibilidades de un artículo y es más bien tema de una

${ }^{*}$ Agradezco el apoyo a esta investigación de S.A.R. el emir Abd al-Aziz b. Fahd, que en los últimos años ha patrocinado diferentes proyectos de investigación sobre la Alhambra, de la que ha edificado una réplica en Riyad.

Copyright: (C) 2017 CSIC. Este es un artículo de acceso abierto distribuido bajo los términos de la licencia de uso y distribución Creative Commons Attribution (CC-by) España 3.0. 
tesis de recopilación ${ }^{1}$. Uno de los aspectos que más admiración ha suscitado de este edificio ha sido el de la epigrafía árabe de sus muros, que de forma tan perfecta embellece todo el conjunto. Esta decoración recibió ya desde su misma concepción una gran atención por parte de los sultanes nazaríes, que utilizaron textos de sus funcionarios más destacados, de sus secretarios de cancillería ( $k u t t a \bar{b}$ al-inš $\bar{a}$ '), para iluminar los más variados elementos arquitectónicos. José Miguel Puerta Vílchez ha demostrado en los últimos tiempos de forma convincente la profunda imbricación entre la poesía y la arquitectura de la Alhambra y el Generalife ${ }^{2}$, que fuerzan a analizar con más detenimiento aún los textos de los propios poemas inmortalizados.

Conocemos los nombres de Ibn al-Ŷayyāb (1274-1349), Ibn al-Jațīb (1313-1374), Ibn Zamrak (1333-c. 1393) e Ibn Furkūn (1380-1417), a los que unió su nombre el monarca Yūsuf III (1376-1417). El dīwān al-inš $\bar{a}$ ', instituido por el rey Muhammad II (1273-1302), debía producir tanto los documentos de cancillería para comunicarse con otras cortes, en especial las del mundo árabo-islámico de su tiempo, como los poemas en honor del sultán (sultāniyyāt) o en las festividades religiosas como el 'id al-aḍhà, en las celebraciones de victorias militares... por esta razón Emilio García Gómez afirmó que la Alhambra era la colección de poemas más bellamente editada ${ }^{3}$. Hoy día no parecen haber llegado hasta nosotros en su forma epigráfica más que los poemas de los tres primeros poetas mencionados. Ibn Furkūn y Yūsuf III compusieron poemas de los que las fuentes históricas guardan memoria, aunque hasta la fecha no ha sido posible localizarlas en el conjunto histórico-artístico y es posible que formaran parte de elementos deleznables que por su naturaleza no han llegado hasta nosotros, o por los caprichos de la historia moderna de la Alhambra, muchas veces convulsa.

Abū 1-Ḥasan 'Alī Ibn al-Ŷayyāb, (1274-1349)4 fue canciller de la corte nazarí de Granada y realizó estudios tanto con juristas como con

${ }^{1}$ El listado sería interminable, desde los traductores del siglo XVI hasta la última aportación, publicada en 2015, es la obra en árabe editada por Akmir y Puerta Vílchez, Qaṣr al-hamrā'.

${ }^{2}$ Puerta Vílchez, "La construcción poética de la Alhambra".

${ }^{3}$ García Gómez, Silla del moro, pp. 89-90.

${ }^{4}$ Rubiera Mata, Ibn al-Ŷyyyāb, el otro poeta de la Alhambra; Rubiera Mata y Kalaitzidou, "Ibn al-Ŷayyāb"; Rubiera Mata, "Estudio introductorio"; Cabanelas Rodríguez, "Inscripciones poéticas del Generalife"; Makarriou, "Etude d'une scenographie poetique"; Ŷarrār, Dīwān al-Hamrā'. 
literatos y, a pesar de las tendencias contrarias a los șufies de algunos de sus maestros, desarrolló una actividad poética profundamente religiosa con especial dedicación a la alabanza del profeta del Islam ${ }^{5}$. Se relacionó con místicos como Abū 'Abd Allāh al-Sāhilī̄, al que dedicó un poema con ocasión de la apertura de una madrasa en Málaga. Formó parte del dīwān al-inš $\bar{a}$ ' desde que tenía alrededor de veinte años y terminó su formación allí bajo la dirección de Ibn al-Hakīm de Ronda $^{7}$. Fue desde este organismo y, posiblemente ya dirigiéndolo tras la muerte de su maestro y antecesor, cuando compuso muchas de las obras que adornan las paredes de la Alhambra, que se convierte en un recinto palaciego extraordinario desde la época de Muḥammad III (1302-1309). Su aportación a la Alhambra puede ser medida gracias al estudio fundamental de María Jesús. Rubiera, que con la ayuda del dīwān editado de este poeta pudo mostrar su relevancia para la epigrafía nazarí ${ }^{8}$.

Su sucesor fue Ibn al-Jațīb (1313-1374) ${ }^{9}$, el Dַu l-wizaratayn [=el doblemente ministro], una de las figuras más polifacéticas de la historia de al-Andalus. No solo escribió obras acerca de los temas más variados, desde la fundamental Al-Ihātạ fì ajbār Garnāta hasta tratados sobre mística, medicina y poemarios de diferentes poetas. Acompañó en su trayectoria, en su destierro y en su vuelta al poder, a Muhammad V, que lo nombró doblemente ministro, siendo una de sus responsabilidades precisamente la dirección del dīwān al-inša $\bar{a}^{\prime}$, al que lo condujo por primera vez su maestro Ibn al-Ŷayyāb, con el que mantuvo una relación extraordinaria. La persecución que sufrió por parte de los nazaríes lo llevó a refugiarse en el reino meriní, donde fue procesado por herejía a instancias de los monarcas granadinos y, finalmente, asesinado, posiblemente por su sucesor en la cancillería y el personaje más relevante de la epigrafía de la Alhambra, Ibn Zamrak. Conservamos el

${ }^{5}$ Rubiera Mata, "Las décimas del Profeta".

${ }^{6}$ Rubiera Mata, "Datos acerca de una "madrasa" en Málaga".

${ }^{7}$ Como veremos más adelante, esta conexión con la ciudad malagueña será importante en el estudio de la inscripción objeto de estas páginas.

${ }^{8}$ Rubiera Mata, Ibn al-Ŷyyyāb, el otro poeta de la Alhambra.

${ }^{9}$ Lirola Delgado, "Ibn al-Jațīb"; Molina López, Ibn al-Jațīb; Santiago Simón, El polígrafo granadino Ibn al-Jațīb y el sufismo; al-'Abbādī, "Los móviles económicos en la vida de Ibn al-Jațīb"; al-'Abbādī, El reino de Granada en la época de Muhammad V; Bosch Vilá, Ben al-Jatib y Granada; Calero Secall, "El proceso de Ibn al-Jațīb". 
dīwān de este poeta, por lo que los fragmentos a él atribuidos en los muros de la Alhambra son de autoría segura ${ }^{10}$.

Su verdugo y sucesor fue el poeta que más se prodigó en la Alhambra, Ibn Zamrak (1333-c.1393), cuya vida y obra conocemos a través de los estudios de Emilio García Gómez ${ }^{11}$. También nos es bien conocido a través de la propia Ihâtạ de Ibn al-Jațīb ${ }^{12}$, quien únicamente incluyó los primeros treinta y cinco años de la vida de su discípulo Ibn Zamrak, y en algunos aspectos gracias a la obra del príncipe nazarí Ibn al-Aḥmar ${ }^{13}$. Estudió en la recién inaugurada madrasa granadina, donde, además de Ibn al-Jatị̂b, recibió clases de los mejores maestros de la época, entre ellos Ibn Marzūq que lo relacionó con grupos sufíes de gran relevancia en el norte de África, cosa que posteriormente le serviría cuando hubo de seguir al destierro a Muhammad V en 1359. Tras su vuelta al poder, y con la ayuda de Ibn al-Jațīb, fue prosperando en la corte nazarí hasta que el maestro huyó al norte de África en 1372, momento en que el propio Ibn Zamrak fue elevado a ministro principal del reino nazarí, cargo desde el que dirigió la cacería de su antiguo maestro hasta conseguir asesinarlo en 1374 en Fez. Las quejas de los hijos del polígrafo granadino quedaron registradas en diferentes obras ${ }^{14}$. Los siguientes años vieron su éxito en la corte nazarí, en la que ejerció de secretario hasta la muerte de Muhammad V en enero de 1391. Al-Maqqarī transmite sus propias palabras:

Le serví [a Muḥammad V] treinta y siete años: tres en el Magreb y el resto en alAndalus. En ellos compuse para él sesenta y seis qașìdas, destinadas a otras tantas fiestas. Todos los versos admirables y las peregrinas alabanzas que hay en sus felices mansiones - tanto en los alcázares y jardines [de la Alhambra] como en los Alixares y la Sabīka; lo mismo en țāqas, țuruz y en otros sitios- son obra mía ${ }^{15}$.

\footnotetext{
${ }^{10}$ Ibn al-Jațīb, Dīwān al-șayyib wa-l-ŷhahàm wa-l-māḍ̂̀ wa-kahām; Fernández Puertas, "Los textos poéticos de Ibn al-Jatib".

${ }^{11}$ García Gómez, Ibn Zamrak el poeta de la Alhambra.

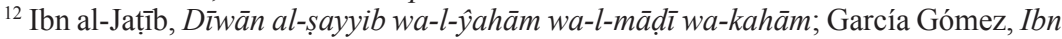
Zamrak el poeta de la Alhambra, pp. 29-30, 49, 55-57.

${ }^{13} \mathrm{Ibn}$ al-Ahmar compuso una obra que permanece manuscrita en la Biblioteca Nacional de París, Slane 2106, Al-Bugya wa-l-darak fì kalām Ibn Zamrak. Su contenido fue vertido por al-Maqqarī en su Nafh al-țīb.

${ }^{14}$ García Gómez, Cinco poetas musulmanes, p. 206; al-Maqqarī, Nafh al-țīb, VII, p. 161.

${ }^{15}$ García Gómez Ibn Zamrak el poeta de la Alhambra, p. 60; Al-Maqqarī, Nafh altīb, II, p. 237.
} 
Tras la muerte del monarca, alternó periodos de favor real con destierros en fortalezas nazaríes, hasta que en 1393 fue asesinado, junto a dos de sus hijos y a sus criados, ante las mujeres de su familia por sicarios de Muḥammad VII. Las fuentes árabes se complacen en enlazar su trágico final con el de su maestro.

Ibn Furkūn fue el último poeta del que conocemos que realizara composiciones poéticas para elementos presentes en la Alhambra, aunque hoy no hay fragmento alguno localizado; Abū 1-Ḥusayn Aḥmad b. Sulaymān $(1380-1417)^{16}$ fue poeta, calígrafo y secretario personal del rey poeta nazarí Yūsuf III. Contamos con pocas menciones a este poeta en fuentes diferentes de sus propias obras, editadas por Muhammad b. Šarīfa, que supone que se debe a la pérdida de algunas partes de obras de Ibn 'Āṣim. Se supone que murió tras el fallecimiento de Yūsuf III, en las luchas internas que afectaron al reino nazarí, aunque ni siquiera esto es seguro, pues podría haber estado vivo por algunas referencias presentes en su dīwān en época de Muḥammad VII. Ibn al-Jațīb ${ }^{17}$ alabó la capacidad de este joven secretario, y Yūsuf III encargó a este poeta que decorase algunas estancias del Generalife, como un nuevo salón sobre la puerta del palacio, para los que compuso los versos que había en las tacas y en los frisos. En el dīwān de Ibn Furkūn hay un análisis muy detallado de las fechas de la construcción y los versos que se grabarían en ellos ${ }^{18}$.

Mención aparte merece Yūsuf III (1376-1417) ${ }^{19}$, el mayor rey poeta de la historia andalusí tras al-Mu'tamid. Fue rey de Granada (14081417) tras suceder a su hermano Muḥammad VII y combatió contra Castilla con suerte alterna, ocupando Priego y Zahara entre 1408 y 1409 , pero sufrió la pérdida de Antequera ante Castilla en 1410 y se vio obligado a solicitar la paz, aunque consiguió recuperar Gibraltar más tarde. Durante su mandato se construyó el palacio que lleva su nombre en la Alhambra, siendo sucedido por su hijo Muhammad VIII.

Las obras de estos poetas se conservan en los muros de la Alhambra y el Generalife, aunque muchas han quedado destruidas y solo conservamos su memoria gracias a las fuentes escritas; así sucede de forma notable con los escritos de Ibn Furkūn y con muchos de Ibn al-Jațīb.

\footnotetext{
${ }^{16}$ Ibn Šarīfa, Dīwān Ibn Furkūn; Ibn Šarīfa, Mažhar al-nūr; Palacios Romero, "Yūsuf III en el dīwān de Ibn Furkūn" y Palacios Romero, "Ibn Furkūn".

${ }^{17}$ Ibn al-Jațīb, Al-Ihātạ fì ajbār Garnāta, I, pp. 220-1.

${ }^{18}$ Ibn Šarīfa, Dīwān Ibn Furkūn, pp. 155-60, 163-4.

${ }^{19}$ Del Moral, "El dīwān de Yūsuf III y el sitio de Gibraltar"; Guennūn, Dìwān mālik Garnātạ; Al-Maqqarī, Azhār al-riyāẹ fì ajbār 'Iyāẹ, pp. 11-176.
} 
Sin embargo, una gran parte de la epigrafía de este conjunto monumental es de tipo religioso, incluyendo diferentes frases coránicas y otras en que se ruega el auxilio divino utilizando lenguaje coránico, común a una gran cantidad de edificios y de inscripciones de época andalusí, tanto nazaríes como almohades e incluso anteriores. Incluso el lema de los nazaríes, $l \bar{a}$ gālib illä Allāh [=no hay vencedor sino Dios] es una frase que figuraba en la bandera blanca del califa almohade Yūsuf Abū Ya'qūb, destacada en el Kitāb raw ḍ al-mi 'țār como el estandarte califal en la batalla de Alarcos ${ }^{20}$. Otras frases de similar dimensión religiosa aparecen en los muros de la Alhambra y del Generalife y han sido abordadas en muchas ocasiones por los estudiosos desde el siglo XVII hasta hoy.

\section{El estudio de las inscripciones árabes de la Alhambra}

El estudio de las inscripciones árabes de la Alhambra ha ocupado al arabismo español desde el principio. Las primeras aportaciones para el conocimiento de este tema aparecen en los trabajos de los moriscos al servicio de la corona española en el siglo XVI ${ }^{21}$, en especial del traductor Alonso del Castillo, que tanta relevancia tuvo, o al menos se le atribuye, en el asunto de los Plomos del Sacromonte ${ }^{22}$. Gracias a su intervención incluso se conservan algunas inscripciones que no han llegado hasta nuestros días, y como se ha podido comprobar dejó de traducir o de consignar algunos textos, algunas inscripciones para evitar que fueran eliminadas, dado su contenido religioso. En el siglo XVIII Miguel Casiri y Pablo Lozano llevaron a cabo algunas lecturas, y algunos dibujos que se conservan en el Gabinete de Antigüedades de la Real Academia de la Historia, obra del pintor Diego Sánchez Sarabia y de los arquitectos Juan de Villanueva y Pedro Arnal, dando así buena muestra del interés ilustrado por la Alhambra ${ }^{23}$. Esta labor fue conti-

\footnotetext{
${ }^{20}$ Ibn Abī Zar', Al-anīs al-muțrib, p. 228.

${ }^{21}$ Noticias contenidas en el manuscrito de la Biblioteca Nacional de Madrid, $\mathrm{n}^{\mathrm{o}} 7453$, Isti 'āb mā bi-Garnāta min aš 'ār wa-l-tawārīj.

${ }^{22}$ Caro Baroja, Los moriscos del Reino de Granada, pp. 208-9; Bernabé Pons, "Los mecanismos de una resistencia".

${ }^{23}$ Martínez Núñez, Epigrafía árabe, Catálogo del Gabinete de Antigüedades, $\mathrm{n}^{\circ} 42$; Puerta Vílchez, "La epigrafía de la Alhambra y de la mezquita de Córdoba en los trabajos académicos del siglo XVIII".
} 
nuada por los arabistas decimonónicos ${ }^{24}$, especialmente por Emilio Lafuente Alcántara y por Antonio Almagro Cárdenas (1879), que fueron los primeros que abordaron la inscripción objeto de este estudio. Durante el siglo $\mathrm{XX}^{25}$ las investigaciones consolidaron y ampliaron el conocimiento de la epigrafía de la Alhambra, en especial gracias a Emilio García Gómez, los trabajos ya mencionados de Darío Cabanelas y de Antonio Fernández Puertas, y a María Jesús Rubiera, y ya en el siglo XXI ha dado frutos extraordinarios, aprovechando las extraordinarias posibilidades que ofrecen tanto la informática ${ }^{26}$ como el tratamiento de imágenes y la muy superior calidad editorial de estos tiempos ${ }^{27}$.

\section{La inscripción de origen desconocido.}

A pesar del esfuerzo desplegado en el estudio de la epigrafía árabe de la Alhambra, tanto desde el mundo árabe como desde el arabismo español, hay un pequeño número de inscripciones, cinco en total, cuyo origen es desconocido hasta la fecha. De ellas tres son de dimensiones muy reducidas, por lo que su localización, además de difícil, parece poco necesaria. En estas páginas queremos centrarnos en una inscripción que sí parece tener relevancia, que aparece en diferentes partes de la Alhambra y el Generalife y que podemos encontrar también en algunas inscripciones de otras partes de Andalucía, así como en el norte de África, especialmente en la ciudad de Fez.

La inscripción es la siguiente:

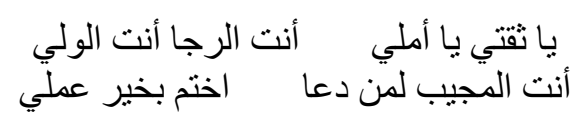

\footnotetext{
${ }^{24}$ Lozano, Antigüedades árabes de España; Lafuente Alcántara, Inscripciones árabes de Granada; Almagro Cárdenas, Estudio sobre las inscripciones árabes de Granada.

${ }^{25} \mathrm{Nykl}$, "Inscripciones árabes de la Alhambra y del Generalife"; García Gómez, Foco de antigua luz sobre la Alhambra.

${ }^{26}$ Castilla Brazales, Corpus epigráfico de la Alhambra: Palacio de Comares.

${ }^{27}$ Puerta Vílchez, Leer la Alhambra. Guía visual del monumento a través de sus inscripciones.
} 
(Metro raŷaz maŷzū, rima lī)

¡Oh mi certidumbre y mi esperanza,

Tú eres el amparo, Tú la confianza!

¡Tú, que respondes a quien Te invoca,

Pon buen sello a lo que hago! 28

Hay una variante de esta inscripción en la que se pierde casi todo el primer hemistiquio del segundo verso y es sustituido por una alusión al profeta del islam, quedando así:

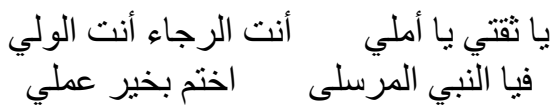

La presencia de variantes en textos poéticos de toda índole ha sido estudiada en profundidad por los especialistas en la etnografía de la actuación ${ }^{29}$, que han determinado diferentes factores en la modificación del texto base, debidas en ocasiones al público al que va dirigido, a dar variedad a la recitación, etc. Y en los últimos años esto ha sido objeto de análisis también en los estudios acerca del sufismo ${ }^{30}$.

La inscripción de la Alhambra aparece también en la Casa del Gigante de Ronda ${ }^{31}$, y en diferentes partes de Málaga, en cuyo museo se conservan diferentes ejemplos ${ }^{32}$, en muchos casos con la variante del primer hemistiquio del segundo verso.

Martínez Núñez denomina a esta inscripción como post-almohade, pues se registra tanto en ámbito nazarí como meriní, y a partir de ahora, mudéjar. El estilo caligráfico es el nasjí33, una escritura cursiva que convivió en las inscripciones ornamentales del reino de Granada con el cúfico; aparece también en un posible funduq en

${ }^{28}$ Puerta Vílchez, Leer la Alhambra. Guía visual del monumento, p. 42 (muro sur del Pabellón de la Victoria), p. 82 (alcobas laterales del Patio de los Arrayanes), p. 253 (pórtico del Partal), p. 332 (en las alacenas de la Torre de la Cautiva), en este caso con la versión en que se menciona al Profeta en el segundo verso sin ninguna anomalía gráfica) p. 332 (mirador del patio de la acequia), p. 339 (Generalife, Pabellón Norte).

${ }^{29}$ Reynolds, Heroic Poets, Poetic Heroes.

${ }^{30}$ Hannoum, Practicing Sufism. Sufi Politics and Performance.

${ }^{31}$ Martínez Núñez et alii, Epigrafía árabe. Catálogo del Gabinete de Antigüedades, pp. 134-135; Martínez Núñez, "Epigrafías árabes de la Casa del Gigante”, pp. 116, 126$128,134$.

${ }^{32}$ Acién Almanza y Martínez Núñez, Catálogo de las inscripciones árabes del Museo de Málaga, no 37, 39 y 52, láminas XLI, XLIV 1 y LVII 1. Esta última, de uso funerario.

${ }^{33}$ Safadi, Islamic Calligraphy; Puerta Vílchez, La Aventura del cálamo. 
Carmona, tal y como nos ha informado la arqueóloga de la ciudad, Rocío Anglada.

El hecho de aparecer una inscripción semejante en un edificio de Carmona sólo podía conducirnos a la existencia de textos semejantes en el Alcázar de Sevilla, ya que como es sabido el monarca Pedro I (1350-1369) mantuvo una relación muy especial tanto con la ciudad de Sevilla, donde mantuvo su corte gran parte de su reinado, como con la ciudad de Carmona, donde construyó un palacio con fuertes reminiscencias de su alcázar sevillano ${ }^{34}$, aunque necesitaríamos muchas más investigaciones arqueológicas y una planimetría más sistemática para poder confirmar la identidad que diferentes autores han establecido entre ambos edificios ${ }^{35}$.

Contamos con numerosas referencias a la importancia de los granadinos durante el reinado de Pedro I, que mantuvo en líneas generales buenas relaciones con los monarcas nazaríes de aquel tiempo, sus vasallos, y recibió de ellos tanto ayuda militar como artesanos para sus construcciones e, incluso, consejo de algunas de las figuras más relevantes del reino, como podemos observar en las obras de Ibn al-Jațî $b^{36}$

Conseguí permiso del sultán, el cual me dejó la elección en el consejo, para dirigirme al rey de los cristianos, entonces afligido. Le aconsejé desconfiara de su pueblo y se mostrara prudente ante las trampas de los que confabulan con su hermano. Le he encomendado igualmente tomar un refugio, elegido por él mismo, para proteger a su hijo y sus tesoros. Lo he argumentado todo citando historias corrientes, así como crónicas famosas para que la guerra civil alcance su tierra. Aceptó la propuesta y agradeció el consejo y eligió para ello la villa de Carmona que se encuentra en las proximidades de su capital, Sevilla ${ }^{37}$.

La relación entre los palacios de Pedro I en Sevilla y el conjunto palatino de la Alhambra ha sido puesta de manifiesto en diferentes ocasiones $^{38}$. De hecho, la inscripción objeto de este estudio es más frecuente en el alcázar cristiano que en el islámico.

En el palacio de Carmona de Pedro I no se ha encontrado esta inscripción, cosa natural dado el estado de destrucción del mismo. Sin

${ }^{34}$ Cómez Ramos, "Alcázar de Carmona versus Alcázar de Sevilla".

${ }^{35}$ Anglada Curado y Galera Navarro, "El Alcázar de Arriba de Carmona", p. 51; Cómez Ramos, El Alcázar del Rey Don Pedro, p. 159.

${ }^{36}$ Manquer, J., "La figura de Ibn al-Jațīb como consejero de Pedro I de Castilla".

${ }^{37}$ Ibn al-Jațīb, Al-Ihạța fi ajbār Garnāța, II, 86. Trad. J. Marquer, p. 5.

${ }^{38}$ Manzano Martos, La Alhambra, el universo mágico de Granada, pp. 119-211. 
embargo, al haberla hallado en una excavación en la misma ciudad, en la denominada Casa Mudéjar de la calle Ancha parece probable que se reutilizara una pieza anterior que formaba parte del palacio.

En el Alcázar de Sevilla encontramos la inscripción, en su primera versión, aunque elimina el primer hemistiquio del segundo verso, en el Patio de la Doncellas ${ }^{39}$, Salón de Carlos V ${ }^{40}$, Dormitorio de los Reyes Moros $^{41}$, Patio de las Muñecass ${ }^{42}$, Sala de los Príncipes ${ }^{43}$, Antesala de Armas de los Reyes Católicos ${ }^{44}$, Salón del techo de Felipe II $^{45}$ y Gabinete de María de Padilla ${ }^{46}$.

También encontró Amador de los Ríos en Sevilla, en la Casa de Olea, en el número 7 de la calle Guzmán el Bueno, una muestra de esta inscripción ${ }^{47}$.

La importancia de esta inscripción en la estética del Alcázar de Sevilla fue ponderada por uno de los principales investigadores del monumento, Rafael Cómez:

No obstante, los ecos de esta muda oración que recorre todo el palacio, llega hasta la alcoba real y en rítmicos nesjíes se eleva "¡Oh confianza mía! ¡Oh esperanza mía! ¡Tú eres mi esperanza, Tú eres mi protector! ¡Sella con la bondad mis obras!”, enlazando un friso de castillos, leones y escudos de la Banda ${ }^{48}$.

El texto no ha recibido la atención que merece, en parte, por la propia dificultad de su lectura. Emilio Lafuente Alcántara realizó un estudio meritorio en que llegó a descifrar el poema en el Mirador del Príncipe ${ }^{49}$ :

${ }^{39}$ Amador de los Ríos, Inscripciones árabes de Sevilla, p. 135.

${ }^{40}$ Amador de los Ríos, Inscripciones árabes de Sevilla, p. 147.

${ }^{41}$ Amador de los Ríos, Inscripciones árabes de Sevilla, p. 155.

${ }^{42}$ Amador de los Ríos, Inscripciones árabes de Sevilla, p. 163.

${ }^{43}$ Amador de los Ríos, Inscripciones árabes de Sevilla, p. 169.

${ }^{44}$ Amador de los Ríos, Inscripciones árabes de Sevilla, p. 174.

${ }^{45}$ Amador de los Ríos, Inscripciones árabes de Sevilla, p. 180.

${ }^{46}$ Amador de los Ríos, Inscripciones árabes de Sevilla, p. 207.

${ }^{47}$ Amador de los Ríos, Inscripciones árabes de Sevilla, pp. 225-226 y p. 231.

${ }^{48}$ Cómez Ramos, El Alcázar del Rey Don Pedro, pp. 66-7.

${ }^{49}$ Lafuente Alcántara, Inscripciones árabes de Granada, pp. 170-171. La lectura de Lafuente Alcántara es correcta, pues el y $\bar{a}$ ' final de al-mursal está en ese epígrafe. La única discrepancia con la lectura correcta es $f a-y \bar{a} l-n a b \bar{l}$ en lugar de $f a-b i-l-n a b \bar{l}$, Puerta Vílchez lee $f a$-bi-l-nabī al-mursali y señala las incorrecciones gramaticales: un alif de más en $f a-$ $b i-l-n a b \bar{\imath}$, lo que justifica la lectura de Lafuente y un $y \bar{a}$ ' final en mursal. 


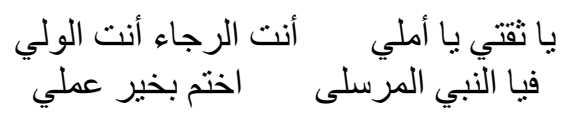

Obviamente hay una pequeña alteración en el primer hemistiquio del segundo verso, que dejan el poema, en la versión del propio Lafuente:

¡Oh confianza y esperanza mía; tú eres mi esperanza, tú eres mi sostén! ¡Oh mi profeta y mi nuncio; concede a mis obras buen éxito!

Es necesario insistir en que, aunque hay un error gramatical en la $y \bar{a}$ ' final de al-mursal, esta se encuentra en efecto en la inscripción, por lo que la lectura de Lafuente fue correcta en este punto.

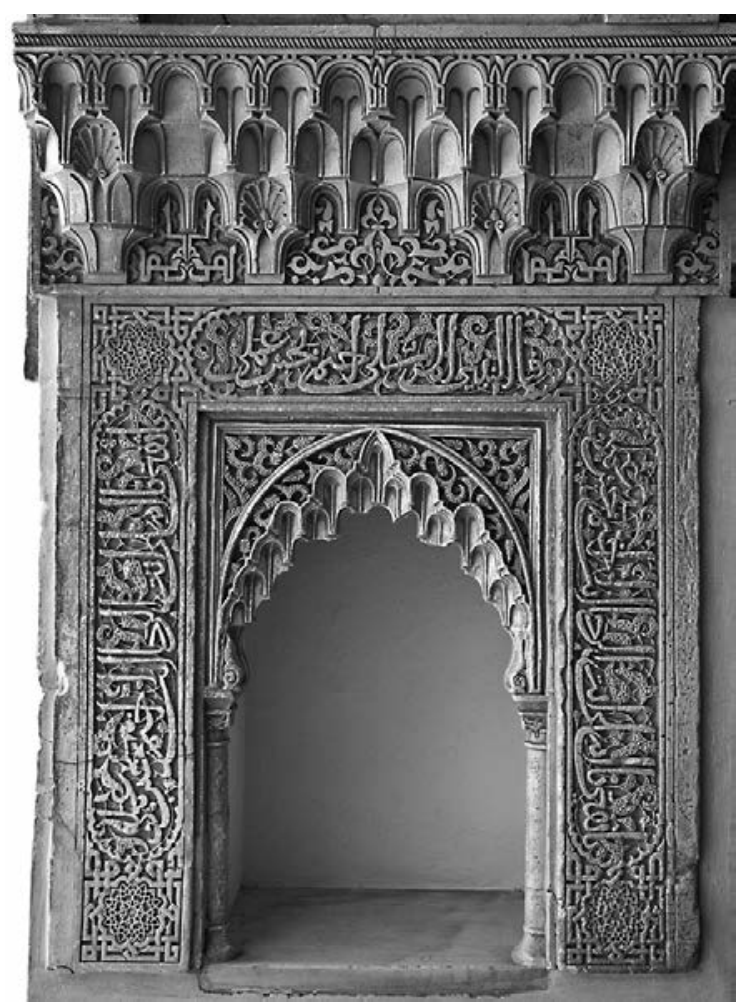

Fig. 2. Taca de la alcoba del Patio de los Arrayanes de la Alhambra. Foto cortesía de editorial Edilux. 
Dado que no leyó correctamente los dos versos en el Cuarto Real ${ }^{50}$, resultó imposible investigar este poema, Lafuente leyó como sigue, sin prestar atención ni en árabe ni en español a la forma métrica:

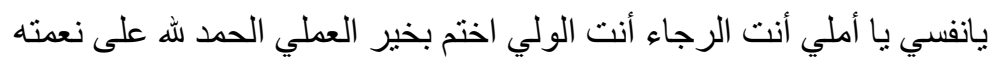

En este caso Lafuente confunde nafsī por tiqatī y la unió a una de las muchas frases con que se impetra el favor divino:

¡Oh alma mía, oh esperanza mía! Tú eres mi esperanza: tú eres mi protector: sella con la bondad mis obras. Loor a Dios por sus beneficios.

Almagro Cárdenas ${ }^{51}$ denominó la torre de Mohammed al Mirador del príncipe de Lafuente Alcántara y mantuvo su misma lectura, aunque varió algo alguna lectura de las inscripciones cercanas.

García Gómez llevó a cabo una breve reseña de la crítica de este poema ${ }^{52}$ en que señala que $\mathrm{Nyk}^{53}$ fue el primero en descifrar esta inscripción. Lafuente ${ }^{54}$ ya lo había llevado a cabo pero había errado parcialmente en la lectura de la misma y García Gómez otorga el mérito a Nykl en la lectura de la inscripción. Zanjado el debate epigráfico de la manera descrita, la versión que ofrece García Gómez es de una mayor elegancia que la de Nykl, hecho que no es de extrañar ${ }^{55}$.

¡Oh mi sostén, mi norte, tú!

Tú eres mi fe, tú mi patrón.

Tú que al que oró contestas sí:

"A mi labor buen sello pon".

${ }^{50}$ Lafuente Alcántara, Inscripciones árabes de Granada, p. 196.

${ }^{51}$ Almagro Cárdenas, Estudio sobre las inscripciones árabes de Granada, p. 37.

${ }^{52}$ García Gómez, Foco de antigua luz sobre la Alhambra, pp. 89-90.

${ }^{53} \mathrm{Nykl}$, "Inscripciones árabes de la Alhambra y del Generalife", p. 176.

${ }^{54}$ Lafuente Alcántara, Inscripciones árabes de Granada, p. 171. De hecho, confunde la palabra $\underline{t}$ iqati $\bar{l}=\mathrm{mi}$ confianza $]$ con $n a f s \bar{\imath}[=\mathrm{mi}$ alma$]$, por lo que no podemos considerar que se tratara de una lectura correcta. Tampoco advierte que las inscripciones señaladas son variantes del mismo poema, aspecto en el que Nykl sí repara.

${ }^{55}$ García Gómez, Foco de antigua luz sobre la Alhambra, pp. 89-90. 


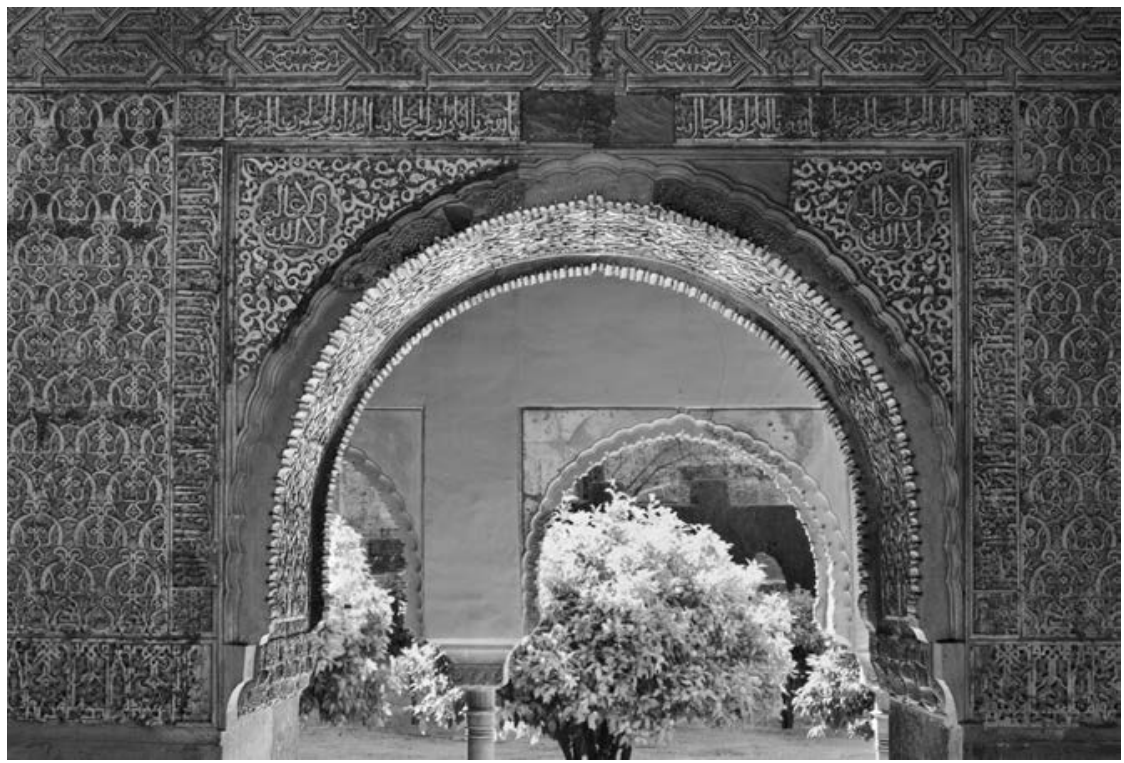

Figura 3. Interior de arco de entrada de la Torre de Machuca. Foto cortesía de la editorial Edilux.

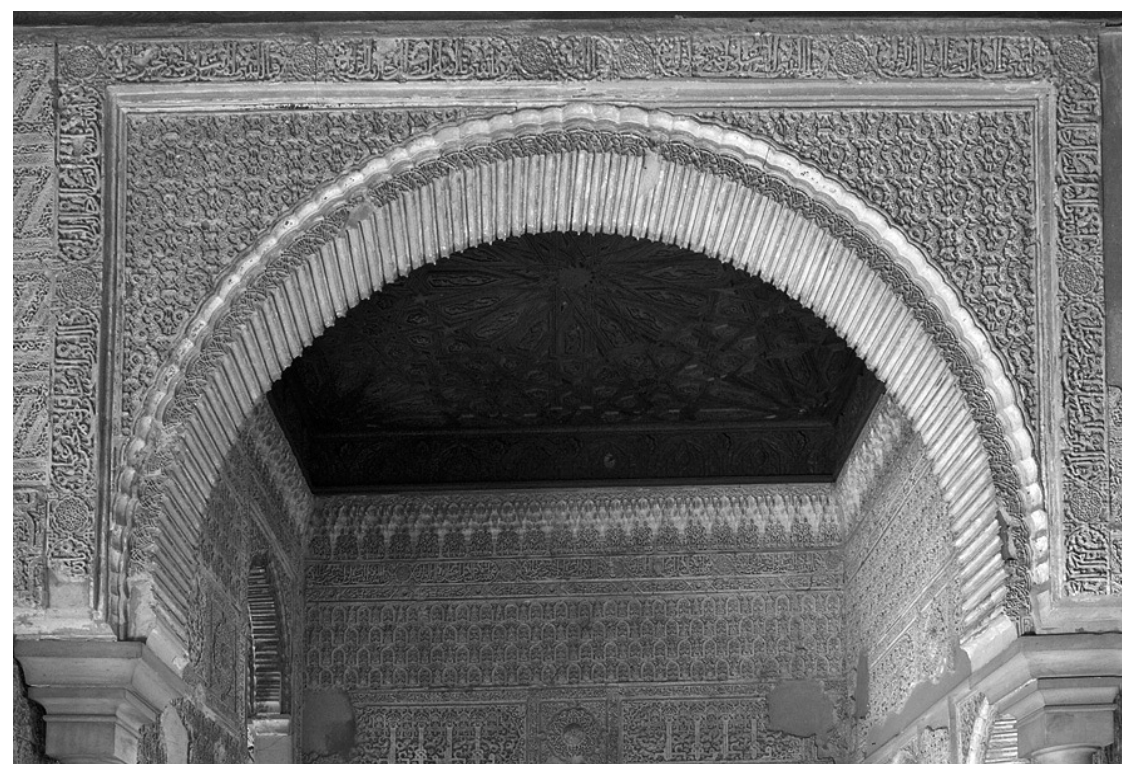

Figura 4. Arco de separación de la Torre del Mirador del Partal. Imagen cortesía de Editorial Edilux. 
De la dificultad de estas inscripciones da testimonio el hecho de que una de las principales especialistas en epigrafía árabe, Carmen Barceló $^{56}$, ofreciera la variante $a l$ - 'imlà en lugar de al-amalì, que tras los trabajos de Martínez Núñez ya podíamos descartar.

En realidad, esta inscripción parece provenir de una narración referida a uno de los primeros místicos del mundo islámico, al-Hasan alBașrī, en una muestra de la predicación de Ibn al-Ŷawzī:

Contaron acerca de al-Ḥasan al-Bașrī —Dios esté satisfecho de él- que dijo: "Entré a ver a un maŷūs — zoroastriano- que se encontraba a las puertas de la muerte. Era de vida irreprochable y con una moral recta, por lo que deseaba que Dios lo dirigiera en el momento de su muerte y se convirtiera al Islam. Le dije: “Cómo estás? ¿Cómo te encuentras?”. Respondió: “Tengo el corazón enfermo, no tengo salud, un cuerpo escuchimizado, sin fuerza, una tumba triste y no tengo compañero, el viaje ante mí es largo y no cuento con provisiones, ni con un camino preciso, ni cuento con un paso, ni un fuego que me proteja, no tengo cuerpo, ni jardín elevado, ni recompensa para mí, ni Señor Justo ni defensa...”. Dijo al-Hasan: "Rogué a Dios que lo reconciliara y me acerqué a él y le dije: "¿Por qué no te conviertes al Islam?”. Él respondió: “La llave está en manos de Dios, y la cerradura aquí", mientras señalaba su pecho, mientras sufría un síncope. Dijo al-Ḥasan: “¡Dios, Señor y Dueño mío, si este maŷūs te hubiera conocido bien antes, su alma habría ido a ti antes de su separación del mundo y del fin de la esperanza!". Se recuperó del ataque, abrió sus ojos, se acercó a al-Ḥasan y dijo: “¡Jeque! ¡Dios ha enviado la llave! Extiende la mano. Doy testimonio de que no hay más dios que Dios, y que Muhammad es Su enviado". Luego, su alma salió de su cuerpo y se dirigió a la misericordia de Dios. Recitaron:

(Metro râyaz maŷzu, rima $l \bar{l}$ )

¡Oh mi certidumbre y mi esperanza,

Tú eres el amparo, Tú la confianza!

¡Tú, que respondes a quien Te invoca,

Pon buen sello a lo que hago!

¡Haz que me arrepienta antes de que acabe mi plazo!

¡Sé mi Señor y mi Dueño! ${ }^{57}$

Como veremos más adelante, estos versos finales eran recitados por un coro de almocríes, que acompañaban las palabras de Ibn al-Ŷawzī, y que servía para reforzar el efecto de la predicación de este gran alfaquí hanbalí. La obra de la que procede este texto de Ibn al-Ŷawzī, Baḥr al-dum $\bar{u}^{`}[=$ Mar de lágrimas] recopila una serie amplia de sermones

${ }^{56}$ Barceló, "Las inscripciones árabes en las yeserías", p. 40, nota 187.

57 'Abd al-Raḥmān b. al-Ŷawzī, Baḥr al-dumū', p. 20. 
que este predicador impartió en Bagdad. Esas lágrimas citadas en el título hacen referencia a la actitud que, según este predicador, debía tener siempre el hombre ante la inminencia de su encuentro con Dios, que debía preparar mediante el arrepentimiento y el temor ante la divinidad.

El personaje principal de esta narración, al-Hasan al-Bașri ${ }^{-58}$ fue el primer exponente de la mística islámica y recordaba de forma insistente el versículo 55:26 del Corán: "Todo lo que hay en la tierra está muriendo, salvo Su rostro”. Acostumbraba a decir a sus seguidores: “ $¡ H i j o s$ de Adán! ¡Moriréis solos, estaréis solos en la tumba y recitaréis solos, y es a vosotros con quien se hará el recuento!". Otra de las máximas repetidas de esta figura señera era: "Estad en este mundo como si nunca hubierais pasado por él y en el otro como si nunca lo fuerais a dejar".

La obra de al-Hasan al-Bașrī en el terreno jurídico había sido conocida y apreciada en al-Andalus ya en el siglo X, pues el jurista Ibn Mufarriŷ al-Funtawrī ${ }^{-59}$ preparó una edición de la obra jurídica de este personaje: Ŷămi 'fiqh al-Hasan al-Bașrī $[=$ Compendio de derecho de al-Ḥasan al-Bașrī̄. El Kitāb al-Kämil de Mubarrad, que gozó de una amplia difusión en al-Andalus y que dio lugar a varios comentarios de la obra, contaba con numerosas citas de este místico en su actividad sufí, que ha sido objeto de estudio de forma repetida ${ }^{60}$.

En la obra del polígrafo cordobés del s. X, Ibn 'Abd Rabbihi, el 'I $q d$ al-fari $d^{61}$, hay numerosas alusiones a esta figura, aunque ninguna que nos lleve a pensar más que en un personaje piadoso y comprometido con el Islam. Su transformación en figura clave de la mística islámica, a la que alaban y sitúan en el origen de este movimiento todos los sufíes posteriores, ha sido objeto de un estudio meritorio ${ }^{62}$. Resulta particularmente llamativo el hecho de que en las fuentes islámicas se intentaba enfatizar la semejanza entre al-Ḥasan al-Bașrī y Jesucristo, indicando que algunos cristianos caían a sus pies engañados por la se-

${ }^{58}$ Schimmel, Mystical Dimensions of Islam, pp. 30-31.

${ }^{59}$ Lirola, "Ibn Mufarriŷ al-Funtawrî"; Pons Boigues, Ensayo bio-bibliográfico, pp. 93-94; Ibn al-Faraḍ̄i, Ta'rīj 'ulamā al-Andalus, no 1358; al-Ḍabbī, Bugyat al-wu'ât, pp. 71-2; al-Humaydī, $\hat{Y} a d w a t$, I, no 10.

${ }^{60}$ Schaeder, "Hasan al-Basri"; Ritter, "Studien zur Geschichte der islamischen Frömmigkeit. 1. Hasan al-Basri"; Schaeder, "Hasan al-Bașrī. Studien zur Frühgeschichte des Islam".

${ }^{61}$ Ibn 'Abd Rabbihī, Al-'Iqd al-farīd, I, pp. 34-40, I, pp. 58-59, 234, 274, II, pp. 220, 229-230, 231, passim.

${ }^{62}$ Sulayman, Early Islam between Mith and History. Al-Hasan al-Bașrī. 
mejanza. Aunque evidentemente se trata de anécdotas apócrifas, no dejan de incidir en el deseo de sustituir por figuras islámicas la atracción ejercida por otras de la tradición religiosa imperante, anteriormente por otras cristianas, para facilitar la asimilación de la población conversa. Mecanismos semejantes los hemos podido documentar tanto en la cultura islámica en otros casos como en la cristiana en relación con figuras paganas ${ }^{63} \mathrm{y}$, curiosamente, puede haber contribuido a facilitar mecanismos de asimilación inversa cuando cambiaron las tornas.

La obra en que aparece la narración es de 'Abd al-Raḥmān b. al$\hat{Y} \operatorname{awzi}^{64}$ (1116-1200/1201), una de las figuras más relevantes del mundo religioso y cultural 'abbāsí de su tiempo. Descendía del primer califa del Islam, Abū Bakr, y fue el alfaquí de la escuela hanbalí más destacado de su tiempo, marcando algunas posturas doctrinales que se convirtieron en uno de los rasgos definitorios de dicha escuela jurídica sunní. Compuso obras en los más diversos campos, pues su capacidad era legendaria y se decía que había compuesto la primera con trece años, y dado su primer discurso ante una multitud con apenas diez. Si bien el número de estudios acerca de esta gran figura no es tan crecido como el de otras figuras del Islam clásico, ha sido constante desde los tiempos de Carl Brockelmann ${ }^{65}$ hasta hoy, en que se reconoce como figura central en la historia de la predicación islámica ${ }^{66}$.

La fama de este gran predicador alcanzó al-Andalus no solo gracias a sus composiciones, que fueron llegando con los estudiantes andalusíes que de forma habitual volvían de hacer la peregrinación a La Meca y de hacer un viaje de estudios para formarse en ciencias islámicas, sino también gracias al testimonio de viajeros como Ibn Ŷubayr, que describe a un ya anciano Ibn al-Ŷawzī en la predicación que presenció el sábado 26 de mayo de 1184 con las siguientes palabras ${ }^{67}$ :

Después, en la mañana del sábado siguiente, estuvimos presentes en la reunión del jeque, del alfaquí, del imām, del único Ŷamāl al-Dīn, el virtuoso Ibn al-Ŷawzī... Era suma y compendio de todos los demás, maravilla de los tiempos, consuelo de

${ }^{63}$ Ramírez del Río, La leyenda de Cardeña y la épica de al-Andalus.

${ }^{64}$ Ibn Katīi, Al-Bidāya wa-l-nihāya, XII, pp. 28-30; Ibn Raŷāb, Dayl 'alà țabaqāt alhanābila, I, pp. 399-434; Ibn al-'Imād, Šadarāt al-dahab, IV, pp. 329-30; Laoust, "Le Hanbalisme sous le califat de Bagdad (241/855-656/1258)".

${ }^{65}$ Edición de la obra de Ibn al-Ŷawzī, Kitāb al-wafā' fì faḍà'il al-muștafà.

${ }^{66}$ Berkey, Popular Preaching and Religious Authority.

${ }^{67}$ Ibn Ŷubayr, Rihla, pp. 262-263. 
los ojos de la fe, jefe de los hanbalíes, especializado en los más altos grados de las ciencias, imam de la comunidad, experto en el palenque de ese oficio, ilustre por la noble superioridad de su elocuencia y la excelencia de su palabra, poseedor de las bridas del discurso en verso como en prosa, buceador en el mar de su inteligencia para sacar preciosas perlas...

(Una) de sus manifestaciones más espléndidas y más prodigiosas, fue cuando subió al almimbar y los almocríes, cuyo número sobrepasaba los veinte lectores, comenzaron la recitación, dos o tres de ellos recitaban una aleya del Corán de diversa manera según un orden que inspiraba emoción y pasión. Cuando terminaban, otro grupo de igual número seguía con una segunda aleya, y continuaron turnándose en la salmodia de las aleyas de las diferentes suras hasta que completaron la recitación. Habían recitado unas aleyas parecidas, tales que la mente [mejor] iluminada no lograría enumerarlas o citarlas en orden. Cuando hubieron terminado, ese imam de condiciones extraordinarias empezó a pronunciar su juṭba con prontitud y mesura, vertiendo en las orejas palabras como perlas

Y las reacciones de la multitud ante sus palabras eran igualmente entusiastas $^{68}$ :

... y los espíritus se derritieron llenos de ardor hasta el punto de que se alzó un clamor y los gemidos se alternaban con los sollozos. Algunos manifestaban su arrepentimiento a gritos y se desplomaban...

La habilidad de este personaje en la predicación era legendaria y ha sido incluso objeto de diferentes estudios por parte de orientalistas ${ }^{69}$, su fama en al-Andalus era ya grande en época almohade. Así, el gran secretario de cancillería Ibn Amīra, componía obras de wa 'z inspirándose en las de Ibn al-Ŷawzī [wa-la-hu wa 'z alà tarīqat Ibn al-ŶYawzī $]^{70}$, además de otras citas en que describe a diferentes andalusíes que fueron alumnos del gran sabio de Bagdad ${ }^{71}$, entre los que podemos destacar al gran místico Ibn 'Arabī ${ }^{72}$, hecho que puede facilitar la comprensión de la popularidad de su obra: un hanbalí de indudable ortodoxia con buenas relaciones con algunos maestros místicos, apreciados por la mayoría de las tarīqa-s sufíes.

La popularidad de Ibn al-Ŷawzī en el reino nazarí de Granada no ofrece dudas. El propio Ibn al-Jatib lo cita en alguna ocasión ${ }^{73}$ y en su

${ }^{68}$ Ibn Ŷubayr, Rihla, p. 263.

${ }^{69}$ Hartmann, "La predication islamique au Moyen Âge: Ibn al-Gawzi et ses sermons (fin du 6e/12e siècle)".

${ }^{70}$ Al-Maqqarī, Nafh al-tị̂, I, p. 201.

${ }^{71}$ Al-Maqqarī, Naf̣h al-tīb, I, pp. 529, 895, 873-874; II, p. 45.

${ }^{72}$ Al-Maqqarī, Nafth al-țīb, I, p. 567. 
biografía en el monumental Nafh al-tī $\bar{b}$, hay fragmentos del predicador iraquí a modo de consejo impartido por un maestro del sabio de Loja ${ }^{74}$. Una figura que tuvo tanta trascendencia en el Occidente del Islam como el predicador Ibn Marzūq alude a esta gran figura del Islam iraquí en diferentes ocasiones ${ }^{75}$, incluso en una obra que en principio no se prestaba a ello; obviamente en las jutbas, de las que hemos conservado un número mucho más reducido, su ejemplo sería más relevante. La vigencia de la obra de este sabio polígrafo de Bagdad se mantuvo incluso hasta la época morisca, como podemos observar por el manuscrito de su obra Salwat al-Ahzzān (ms. Junta XXXVIII), que muestra su aprecio incluso entre los musulmanes que permanecieron en España tras la caída del reino de Granada ${ }^{76}$.

Uno de los principales trabajos referentes a la predicación islámica a lo largo de la historia señala a Ibn al-Ŷawzī como una de las principales luminarias de este campo ${ }^{77}$. El uso de un coro para reforzar las palabras del orador nos sugiere que, si bien es cierto que el teatro en su concepción griega se había perdido en el Oriente Medio islámico, como tan brillantemente lo evoca Borges en su obra acerca de Averroes $^{78}$, el aprecio por los elementos dramáticos no se había perdido por entero en esta región. La renovación ideológica del mundo islámico de Oriente Medio, producida en parte como reacción a las cruzadas, se expandió posteriormente al Magreb y a al-Andalus, junto con un buen número de instituciones como las madrasas. La presencia de este poema en los muros de la Alhambra no es, en modo alguno, un capricho de un artesano ni una casualidad. Representa ese cordón umbilical de al-Andalus con el Oriente Medio araboislámico ${ }^{79}$.

\footnotetext{
${ }^{73}$ Ibn al-Jatị̂, Kitāb a 'māl al-a ' lām, p. 38.

${ }^{74} \mathrm{Al}$-Maqqarī, Nafh al-țīb; Del Moral, "Un monumento literario a la memoria de Ibn al-Jațīb", p. 216.

${ }^{75}$ Ibn Marzūq El Musnad: hechos memorables de Abū l-Hasan, p. 229 (menciona que las obras de Ibn al-Ŷawzī formaban parte importante del programa de estudios que siguió), 317 (mencionándolo como autoridad en hadīt ) y 399 (señala que había tratado del significado del término șüfi y que una de sus obras era de consulta indispensable sobre el tema).

${ }^{76}$ Hermosilla, "La leyenda de Barșișa según el ms. 63/2 j".

${ }_{77}$ Berkey, Popular Preaching and Religious Authority, pp. 25, 40, 48, 50, 53-54, 59, $88,94-95$

${ }^{78}$ Borges, El Aleph.

${ }^{79}$ Ramírez del Río, La Orientalización de al-Andalus; Ramírez del Río, El libro de las batallas de Ibn Abd Rabbihi.
} 
Además de las apariciones señaladas tanto en el arte nazarí como en el mudéjar, encontramos ejemplos de esta inscripción en mezquitas y madrasas del norte de África, algo ya señalado por Martínez Núñez ${ }^{80}$, como en las mezquitas de $\mathrm{Fez}^{81}$ y en la mezquita de Tremecén (Argelia ${ }^{82}$. Tanto en Málaga como en Fez aparece esta inscripción en contextos funerarios.

En Fez encontramos una variante de este poema un tanto peculiar, y que por su métrica ya resulta obvio que no forma parte del mismo:

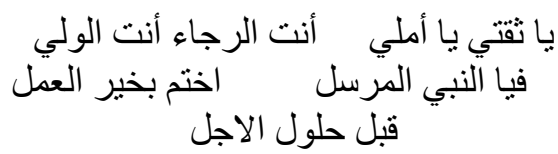

El texto de la tercera línea tendría el sentido de "antes del final del plazo". Dicho texto aparece en la Madrasat al-'Aț̣āīīn ${ }^{83}$, el último monumento erigido en Fez por Abū Sa'īd 'Uțmān (1310-1331), en las puertas situadas frente al vestíbulo, en la fachada oeste; también aparece en la Madrasa Mișbahiyya ${ }^{84}$, la única erigida en Fez por Abū 1Hasan (1331-1351) tras llegar al poder y en la mezquita del cementerio de $\mathrm{Fez}^{85}$. Todos estos edificios contienen, además de la inscripción indicada, muchas otras presentes en el programa epigráfico de la Alhambra.

\footnotetext{
${ }^{80}$ Martínez Núñez, Epigrafía árabe, p. 134; Martínez Núñez, "Epigrafías árabes de la Casa del Gigante", p. 134, nota 127.

${ }^{81}$ Bell, "Inscriptions arabes de Fès", pp. 233-4, en que el segundo verso está completo, con su primer hemistiquio, aunque sin la $y \bar{a}$ ' final de mursili de la Alhambra; por tanto más correcta desde un punto de vista gramatical.

${ }^{82}$ Marçais, Les monuments árabes de Tremecen, pp. 316-317, en que localiza una inscripción con el texto objeto de nuestro estudio, de factura un tanto torpe, en la mezquita de Mechouar, de Tremecén. Marçais identificó esta inscripción precisamente gracias a la bibliografía española: Amador de los Ríos, Inscripciones árabes de Sevilla, pp. 135, 155, 174 y Almagro Cárdenas, Estudio sobre las inscripciones árabes de Granada, pp. 37, 176, 186. Marçais señaló que era una inscripción frecuente en Sevilla y Granada. Más recientemente la revista del IMA (París) Alqantara publicó una breve noticia acerca de este templohttp://archive.wikiwix.com/cache/?url=http $\% 3 \mathrm{~A} \% 2 \mathrm{~F} \% 2 \mathrm{Fwww}$.qantara-med.org $\% 2 \mathrm{Fqa}$ ntara4\%2Fpublic\%2Fshow_document.php\%3Fdo_id\%3D748\%26lang\%3Dfr. Consultado el 06-10-2017

${ }^{83}$ Lhaj Moussa, Étude des inscriptions mérinides de Fas, pp. 103-4.

${ }^{84}$ Lhaj Moussa, Étude des inscriptions mérinides de Fas, pp. 132-3.

${ }^{85}$ Lhaj Moussa, Étude des inscriptions mérinides de Fas, pp. 229-32.
} 


\section{A modo de conclusión}

Los versos acerca de al-Hasan al-Bașrī compuestos posiblemente por Ibn al-Ŷawzī, entraron en al-Andalus gracias a la obra del más famoso predicador de Oriente en el s. XII. La fama del primero, muy apreciado por los círculos sufíes de Granada, se veía respaldada por la impecable ortodoxia del segundo, líder de la corriente hanbalí en Iraq, lo que resultaba muy conveniente. Por otro lado, hacía alusión a una narración en la que un no-musulmán se convierte al Islam, cosa que podía constituir un objetivo claro para los últimos andalusíes, los granadinos, acosados por todos lados por su enemigo cristiano. Por ello resulta natural que el lugar en el que se produjo este motivo, además de en Granada, fuera en Fez y en Ronda, donde los grupos sufíes alcanzaron un grado de influencia muy grande, y de ahí pasara a Carmona y Sevilla, por lo que podemos documentar la presencia de esta inscripción en la España mudéjar. Posiblemente el motivo de la conversión al Islam debía ejercer una atracción aún superior entre los mudéjares castellanos.

La manera en que se produce la transmisión, en que se alternan en el primer hemistiquio del segundo verso dos fórmulas diferentes, además de la simple eliminación del primer hemistiquio del segundo verso, nos lleva a pensar que este texto, además de su transmisión libresca, tuvo un recorrido notable en los discursos de los más destacados predicadores, que posiblemente imitaran las alternancias que pudimos observar en la narración relativa a los almocríes de Bagdad, que cambiaban el orden de los versículos para captar la atención de los fieles de una manera más dinámica. Tampoco podemos descartar que estos versos fueran utilizados en sesiones místicas, donde este tipo de variaciones en la recitación también han sido registradas anteriormente.

La introducción de este motivo posiblemente se produjo en tiempos de Ibn al-Ŷayyāb, cuya relación con el rondeño Ibn al-Ḥakim, su antecesor en el diwān al-inša $\bar{a}$, también con importantes conexiones con grupos sufíes, reforzados tras su viaje a Oriente y por sus conexiones familiares. La única propuesta avanzada hasta la fecha acerca de la introducción de estos versos en el programa epigráfico nazarí nos remite a Muhammad III (1302-1309) ${ }^{86}$, lo que reduce nuestras posibilidades

${ }^{86}$ Martínez Núñez, “Epigrafías árabes de la Casa del Gigante”, p. 135. 
a la hora de sugerir al introductor de estos versos. Ibn al-Ŷayyāb además era conocido por su devoción por el profeta Muhammad.

Consideramos que esta inscripción puede ofrecernos una clave para entender la evolución de algunos aspectos de la cultura granadina andalusí en sus últimos años y esperamos poder aprovecharlos en futuros trabajos.

El uso de una oración por la conversión al Islam en un edificio como el palacio de Pedro I de Sevilla no pudo pasar inadvertido a los altos dignatarios de la Granada nazarí. Era una fórmula diferente de la gāliba o de otras leyendas de tipo religioso, pues la potencia de Dios o su dominio sobre el ser humano puede ser compartido por musulmanes y por cristianos; el ruego por la conversión al Islam no. Sin embargo, no disponemos de documentación para continuar este argumento y debemos simplemente señalar este hecho.

\section{Bibliografía}

'Inān, Muḥammad 'Abd Allāh, Lisān al-Dīn Ibn al-Jațīb. Ațāru-hu wa-turātu-hu al- 'ilmī, El Cairo, 1968.

Acién Almansa, Manuel y Martínez Núñez, María Antonia, Catálogo de las inscripciones árabes del Museo de Málaga, Madrid, Ministerio de Cultura, 1982.

Akmir, Abdeluahed y Puerta Vílchez, José Miguel, Qașr al-Hamrā'. Dākirat alAndalus, Granada - Rabat, Edilux - Markaz dirāsāt al-Andalus wa-ḥiwār alhadāāāt, 2015.

Al-'Abbādī, Aḥmad Mujtār, "Los móviles económicos en la vida de Ibn al-Jaṭîb", Al-Andalus, 20 (1955), pp. 214-221.

Al-'Abbādī, Aḥmad Mujtār, El reino de Granada en la época de Muhammad V, Madrid, Instituto de Estudios Islámicos de Madrid, 1973.

Al-Ḍabbī, Bugyat al-wu 'āt, ed. al-Abyārī, El Cairo, Dār al-kitāb al-mașrī al-lubnan̄i, 1990.

Al-Ḥumaydī, Ŷadwat, ed. al-Abyārī, El Cairo, Dār al-kitāb al-mașrī, 1991.

Almagro Cárdenas, Antonio, Estudio sobre las inscripciones árabes de Granada, Granada, Imprenta Ventura Sabatel, 1879.

Al-Maqqarī, Azhār al-riyāẹ fì ajbār 'Iyāẹ, El Cairo, 1939.

Al-Maqqarī, Naf̣h al-țīb., ed. R. Dozy, Leiden, Brill, 1967.

Al-Maqqarī, Nafḥ al-ṭ̂̀b, ed. Iḥsān 'Abbās, Beirut, Dār Șādir, 1968.

Amador de los Ríos, Rodrigo, Inscripciones árabes de Sevilla, Madrid, Imprenta de T. Fontanet, 1875.

Anglada Curado, Rocío y Galera Navarro, Ventura, "El Alcázar de Arriba de Carmona", Castillos de España 125 (2002), pp. 47-52. 
Barceló, Carmen, "Las inscripciones árabes en las yeserías y alicatados del Cuarto Real de Santo Domingo", en Basilio Pavón Maldonado, El cuarto Real de Santo Domingo de Granada (Los orígenes del arte nazarí), Granada, Ayuntamiento, 1991, pp. 134-50.

Bel, Alfred, "Inscriptions arabes de Fès",

Berkey, Jonathan, Popular Preaching and Religious Authority in the Medieval Islamic near East, Seatle, University of Washington Press, 2001.

Bernabé Pons, Luis Fernando, "Los mecanismos de una resistencia: los Libros plúmbeos del Sacromonte y el Evangelio de Bernabé”, Al-Qantara, 23/2 (2002), pp. 477-98.

Borges, Jorge Luis, El Aleph, Madrid, Alianza, 1984.

Bosch Vilá, Jacinto, Ben al-Jatib y Granada, Madrid, Asociación Cultural Hispano-Alemana, 1980.

Cabanelas Rodríguez, Darío, "Inscripciones poéticas del Generalife", Cuadernos de la Alhambra, 14 (1978), pp. 3-86.

Calero Secall, María Isabel, "El proceso de Ibn al-Jațīb”, Al-Qantara, 22 (2001), pp. 421-49.

Caro Baroja, Julio, Los moriscos del Reino de Granada, Barcelona, Istmo, 2000.

Castilla Brazales, Juan, Corpus epigráfico de la Alhambra: Palacio de Comares, Granada, Patronato de la Alhambra y el Generalife, 2007.

Cómez Ramos, Rafael, "Alcázar de Carmona versus Alcázar de Sevilla”, Laboratorio de Arte, 19 (2006), pp. 9-30.

Cómez Ramos, Rafael, El Alcázar del Rey Don Pedro, Sevilla, Diputación Provincial, $2006^{2}$.

Fernández Puertas, Antonio "Los textos poéticos de Ibn al-Jatib y los coránicos del salón de Comares (la qubba del sultán Yusuf I", Miscelánea de Estudios Árabes y Hebraicos, 60 (2011), pp. 123-51.

García Gómez, Emilio, Cinco poetas musulmanes. Biografias y estudios, Madrid, Espasa-Calpe, 1959.

García Gómez, Emilio, Foco de antigua luz sobre la Alhambra. Madrid, Instituto de Estudios Islámicos de Madrid, 1987.

García Gómez, Emilio, Silla del moro, Madrid, Espasa-Calpe, 1959.

García Gómez, Emilio, Ibn Zamrak, el poeta de la Alhambra. Granada, Patronato de la Alhambra, 1975.

Guennun, A. A. (ed.), Dīwān mālik Garnātạ Yūsuf al-țāliț, Tetuán, Instituto Muley al-Hasan, 1958.

Hannoum, Abdelmagid (ed.), Practicing Sufism. Sufi Politics and Performance, Londres, Routledge, 2016.

Hartmann, "La predication islamique au Moyen Âge: Ibn al-Gawzi et ses sermons (fin du 6e/12e siècle)".

Hermosilla, María José, "La leyenda de Barșișa según el ms. 63/2 j”, Al-Qantara, 9 (1988), pp. 121-36. 
Ibn 'Abd Rabbihī, Al- 'Iqd al-farīd, ed. Aḥmad Amīn et alii, El Cairo, 1948-1953. Ibn Abī Zar', Al-Anīs al-muțib bi-rawọ al-mi 'ṭār, Rabat, Dār al-Manșūr, 1972.

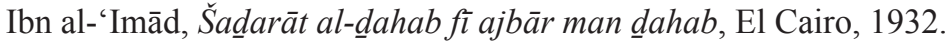

Ibn al-Faraḍ̄̄, Ta'rīj 'ulamā al-Andalus, ed. Al-Abyārī, El Cairo, 1990.

Ibn al-Jaṭīb, Al-Ihāạta fì ajbār Garnāta, El Cairo, 1974.

Ibn al-Jaṭīb, Dīwān al-ṣayyib wa-l-ŷahām wa-l-māḍ̂̀ wa-kahām, Argel, 1973.

Ibn al-Jațīb, Kitāb a 'māl al-a 'lām, trad. Rafaela Castrillo, Madrid, Instituto Hispano Árabe de Cultura, 1983.

Ibn al-Ŷawzī, 'Abd al-Raḥmān, Baḥr al-dumū', ed. Rāšid al-Jalīlī. Beirut, AlMaktaba al-'așriyya, 2010.

Ibn Katīr, Al-Bidāya wa-l-nihāya, ed. A. Abū Mulhim et alii, El Cairo, 1988.

Ibn Marzūq, El Musnad: hechos memorables de Abū l-Hasan, estudio, traducción, anotación e índices de María Jesús Viguera Molins, Madrid, Instituto Hispano Árabe de Cultura, 1977.

Ibn Raŷāb, Dayl 'alà țabaqāt al-ḥanābila, ed. M. Hāmid, El Cairo, 1953.

Ibn Šarīfa, Muhammad, Dīwān Ibn Furkūn, Rabat, Akadimiyya al-Mamlaka alMagribiyya, 1987.

Ibn Šarīfa, Muḥammad, Maẓhar al-nūr, Rabat, Maṭba'at al-Nayah al-Ŷ̃adīda, 1991.

Ibn Ŷubayr, Riḥla, traducción y estudio Felipe Maíllo, Barcelona, Serbal, 1999.

Lafuente Alcántara, Emilio, Inscripciones árabes de Granada, Madrid, s.e., 1959.

Laoust, Henri, "Le Hanbalisme sous le califat de Bagdad (241/855-656/1258)", Revue des études islamiques, 1 (1959), pp. 67-128.

Lhaj Moussa, Aouni, Étude des inscriptions mérinides de Fas, These de Doctorat sous la direction de Solange Ory. Université de Provence, Aix-Marseille 1, febrero de 1991.

Lirola Delgado, Jorge y otros, "Ibn al-Jațīb", en Jorge Lirola (ed.), Biblioteca de al-Andalus, Almería, Fundación Ibn Tufayl, 2004, 3, pp. 643-698.

Lirola Delgado, Jorge, "Ibn Mufarriŷ al-Funtawrī”, en Jorge Lirola (ed.), Biblioteca de al-Andalus, Almería, Fundación Ibn Tufayl, 2004, 2, nº 827.

Lozano, Pablo, Antigüedades árabes de España. Parte segunda que contiene los letreros arábigos que quedan en la Alhambra y algunos de la ciudad de Córdoba, Madrid, 1804.

Makarriou, Sophie, "Etude d'une scenographie poetique: l'oeuvre d'Ibn al-Jayyab à la tour de la Captive (Alhambra)", Studia Islamica 96 (2004), pp. 95-107.

Manzano-Martos, Rafael, La Alhambra, el universo mágico de Granada, Madrid, Anaya, 1992.

Marçais, Georges, Les monuments árabes de Tremecen, París, A. Fontemoing, 1903.

Marquer, Julie, "La figura de Ibn al-Jațīb como consejero de Pedro I de Castilla: entre ficción y realidad", E-Spania. Revue interdisciplinaire d'études hispaniques medievales et modernes, 12 (2011), pp. 1-12. 
Martínez Núñez, María Antonia, "Epigrafías árabes de la Casa del Gigante", Memorias de Ronda. Revista de Historia y Estudios Rondeños, 2 (2006), pp. 109-35.

Martínez Núñez, María Antonia, Epigrafía árabe, Madrid, Real Academia de la Historia, 2007.

Molina López, Emilio, Ibn al-Jațīb, Granada, Comares, 2001.

Moral Molina, Celia del, "El dīwān de Yūsuf III y el sitio de Gibraltar", Homenaje al profesor Dario Cabanelas, Granada, Universidad, 1987, I, 76-96.

Moral, Celia del, "Un monumento literario a la memoria de Ibn al-Jațīb: el Nafh al-țīb de Al-Maqqarı̄”, en Bárbara Boloix, María Dolores Rodríguez y Antonio Peláez (eds.), Saber y poder en al-Andalus: Ibn al-Jațīb, Granada, Universidad, 2014, pp. 206-25.

Nykl, Alois Richard, "Inscripciones árabes de la Alhambra y del Generalife", $A l$ Andalus, 4 (1936), pp. 174-194.

Palacios Romero, Antonio, "Ibn Furkūn”, en Jorge Lirola (ed.), Biblioteca de alAndalus, Almería, Fundación Ibn Tufayl, 1999, III, pp. 179-84.

Palacios Romero, Antonio, "Yūsuf III en el dīwān de Ibn Furkūn", Al-AndalusMagreb, 7 (1999), pp. 255-69.

Pons Boigues, Francisco, Ensayo bio-bibliográfico, Madrid, Real Academia de la Historia, 1898.

Puerta Vílchez, José Miguel "La epigrafía de la Alhambra y de la mezquita de Córdoba en los trabajos académicos del siglo XVIII", en Antonio Almagro (ed.), El legado de al-Andalus. Las antigüedades árabes en los dibujos de la Academia, Madrid, Real Academia de San Fernando, 2015, pp. 107-125.

Puerta Vílchez, José Miguel, "La construcción poética de la Alhambra", Revista de poética medieval, 27 (2013), pp. 263-285.

Puerta Vílchez, José Miguel, La Aventura del cálamo. Granada, Edilux, 2007.

Puerta Vílchez, José Miguel, Leer la Alhambra. Guía visual del monumento a través de sus inscripciones, Granada, Edilux, 2010.

Ramírez del Río, José, El libro de las batallas de Ibn Abd Rabbihi, Madrid, Boreal, 2003.

Ramírez del Río, José, La leyenda de Cardeña y la épica de al-Andalus, Sevilla, Signatura, 2001.

Ramírez del Río, José, La Orientalización de al-Andalus. Los días de los árabes en la península Ibérica, Sevilla, Universidad, 2002.

Reynolds, Dwight, Heroic Poets, Poetic Heroes: The Ethnography of Performance in an Arabic Oral Epic Tradition (Myth and Poetics), Ithaca, Cornell University Press, 1995

Ritter, Hellmut, "Studien zur Geschichte der islamischen Frömmigkeit. 1. Hasan al-Basri”, Der Islam 21 (1933), pp. 1-18

Rubiera Mata, María Jesús, "Estudio introductorio" en E. Lafuente, Inscripciones árabes de Granada, Granada, Universidad, 2000. 
Rubiera Mata, María Jesús, "Las décimas del Profeta, versos con epanadiplosis en la poesía hispano-árabe", Al-Qantara 1 (1980), pp. 55-64.

Rubiera Mata, María Jesús, Ibn al-ŶYayāb. El otro poeta de la Alhambra, Granada, Patronato de la Alhambra, 1982.

Rubiera Mata, María Jesús y Kalaitzidou, Mariana, "Ibn al-Ŷayyāb”, en Jorge Lirola (ed), Biblioteca de al-Andalus, 6, Almería, Fundación Ibn Tufayl, 2009, pp. 129-133.

Rubiera Mata, María Jesús: "Datos acerca de una "madrasa" en Málaga anterior a la nașrī de Granada”, Al-Andalus, 35 (1979), pp. 223-226.

Safadi, Yasin, Islamic Calligraphy, Londres, Shambhala, 1979.

Santiago Simón, Emilio de, El polígrafo granadino Ibn al-Jatīb y el sufismo. Aportaciones para su estudio, Granada, Diputación, 1983.

Schaeder, Hans Hellmut, "Hasan al-Bașrī. Studien zur Frühgeschichte des Islam”, Der Islam, 14 (1925), pp. 1-75.

Schimmel, Anne Marie, Mystical Dimensions of Islam, Chapel Hill, The University of North Carolina Press, 1975.

Schraeder, Hans Hellmut, "Hasan al-Basri”, Der Islam 13 (1923), pp. 1-83.

Sulayman, Ali Mourad, Early Islam between Mith and History. Al-Hasan al-Bașrī (d. 110 H/728 d.C), and the Formation of His Legacy in Classical Islamic Scholarship, Leiden, Brill, 2006.

Ŷarrār, Șalāh, Dīwān al-Hamrā', 'Amman, Dār al-Fāris, 1999.

Recibido: $11 / 02 / 2016$

Aceptado: 16/10/2018 